\title{
SOCIO-ECONOMIC REGIONAL STRATEGIES DEVELOPMENT FORESIGHTING BY PROVIDING ENVIRONMENTAL BALANCE
}

\author{
Natalia S. Mushketova ${ }^{1}$, Jameel S.M. Al-Duraye ${ }^{1, *}$, Tatiana L. Kosulnikova ${ }^{2}$, and Yekaterina P. Yevstifeyeva ${ }^{2}$ \\ ${ }^{1}$ Volgograd State University, Volgograd, Russia \\ ${ }^{2}$ Volgograd State Agricultural University, Volgograd, Russia
}

\begin{abstract}
Long-term forecasting of socio-economic processes is the basis for ensuring regional security. In a crisis, the mechanisms of a market economy are always aimed at constant reforming of economic science in order to ensure the ecological balance and responsible resource consumption. The foresight method as a long-term forecasting, carried out to build routes for future development, is becoming one of the most relevant in developed market economies countries. Foresight of the future and the application of methods for changing it at the world, macro and micro levels determine the search for solutions by the authorities in the development of socio-economic policy that does not violate the ecological balance. It is clear that the constant change of paradigms in the ecological and socio-economic course of the real life of society significantly complicates the foresight processes at the macro and micro levels, causing the transformation of already established plans, programs, projects of environmental and socio-economic policy. The economic crisis at the beginning of 21 st century, which lasts for the second decade, was complicated by the conditions of a pandemic, the forced measures of which are to slow down the processes of production and consumption. At present, using of foresight system is aimed at achieving achievements that are subordinate to national goals, which it is advisable to confirm with the apparatus of mathematical models and system analysis in substantiating the methodological foundations of the ecological balance.
\end{abstract}

\section{Introduction}

Currently, accelerating changes as the main feature of the modern world determine the dynamism of the economy. Dynamism manifests itself in all areas of life: in technological development, in the ecological state, in the economic activity of the population, and so on. The requirements for foresight formation that ensuring environmental safety in regional development, are identical to the requirements for managing a complex dynamic system, which must meet the parameters of flexible adaptation based on the ability to quickly and clearly respond to dynamically changing conditions in the internal and external environment. Obviously that foresight requirements of regional economic system increase from the position of greater opportunities and efficiency of mobilizing actions in comparison with the cumbersome national economy, a system consisting of many regions. In other factors, foresight of environmental safety is necessary to take into account the significant impact on the socio-economic development of both objective conditions (localization of the region, its natural and human resources) and subjective (competent activities of regional authorities aimed at long-term forecasting; attitude to technological progress in digital economy conditions; distrust and rejection of sustainable development provisions region's population.
Dynamism is the driver of world transformation, country, region, local level. Needs that induce action transform the world, which can be both beneficial and defective. Of course, global environmental disasters that threaten the safety of the population are the result of human activity. Such activity, difficult to predict and poorly managed, involves regulation and activation of compensating mechanisms, which can also have an ambiguous result. The consequence of such a crisis situation in all spheres of economic activity has become a systemic approach, which assumes the future predictive perception of the world as a complex system based on systems thinking [1].

\section{Discussions}

Research shows that developed countries use long-term foresight cycles of territories in government programs up to 50 years, with a breakdown into 5-10-year periods $[2,3]$. It should be noted that the course of history, which determines the direction of socio-economic processes evolution, has always had a general vector aimed at improving the life quality. The aspiration of mankind, in a significant part of it, for favorable environmental conditions, predetermines scientific and technological progress. It is advisable to note that progress in society occurs both in the technological order and in the ethical and moral coordination of society

* Corresponding author: gameelmlh@gmail.com 


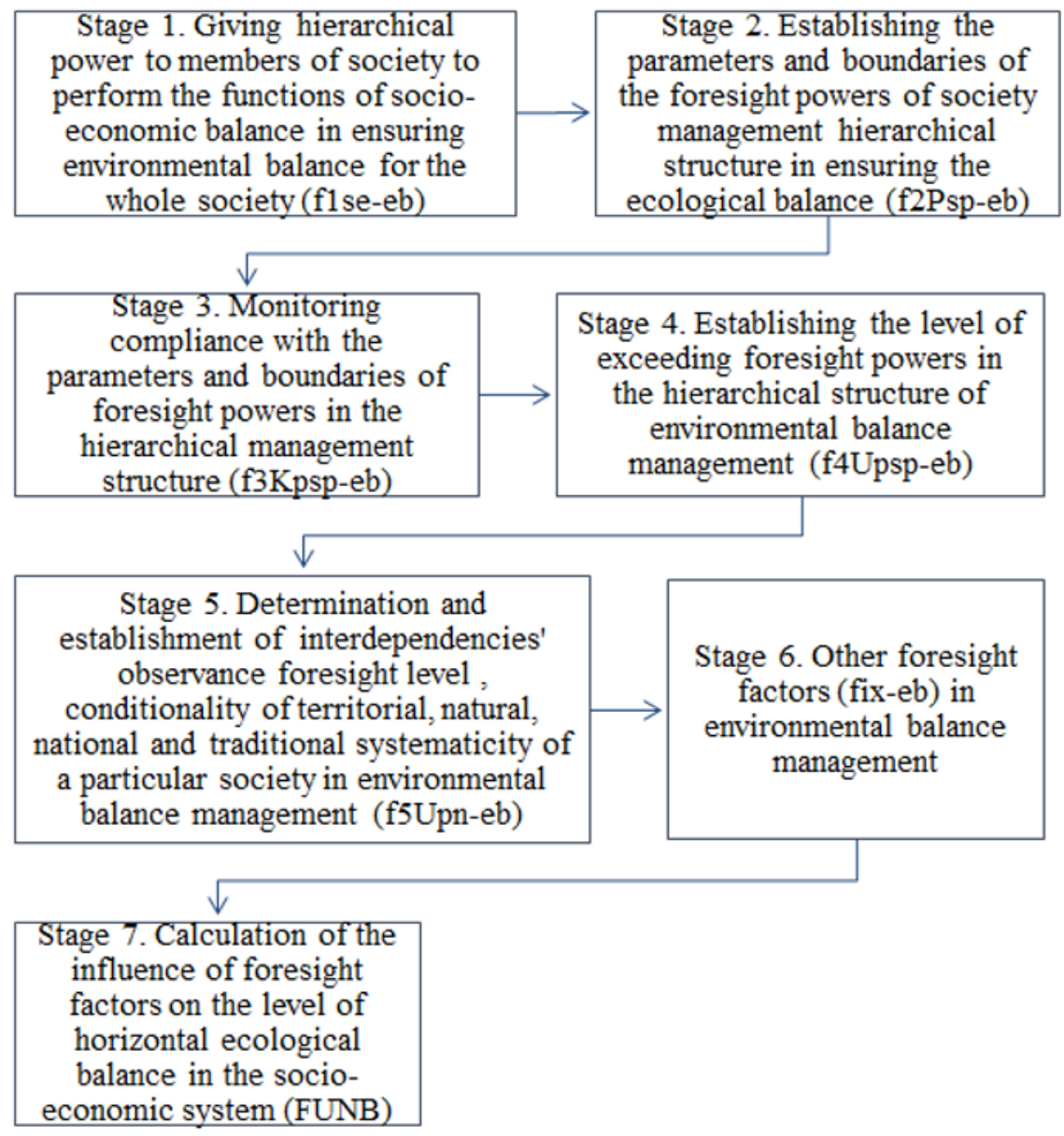

Fig. 1. General conditions for ensuring socio-economic balance in ensuring environmental balance from a foresight perspective (FGser) (Source: compiled by the authors).

roles. It is important to focus on ancient thought, which stood at the origins problems solution of social progress, forming its criteria and directions. The achievements of ancient philosophers are confirmed in the studies of Dicaearchus, Varro, Lucretius Kara, which substantiate the emergence of economic and economic criteria. The the socio-political genesis trend appears in the philosophy of Socrates, Plato, Aristotle. The axiological direction is formed in the writings of the Stoics and Epicurists. In turn, thought of medieval philosophers' evolution took place on the awareness of metaphysical basis of progress essence, ascending to divine transcendentalism.

That is why the problem of the hierarchy of management, built in society when the economic and volitional powers of one person are exceeded over another, is a source of injustice that upsets the balance of horizontal relationships (previously agreed upon). Such a violation will always strive for horizontal balance, for socio-economic equality and development.

The research shows that the horizontal balance in the socio-economic system is ensured by the framework of powers in the hierarchical structure. In the works of the great thinkers I. Kanat and G. Hegel, who at one time clearly reflect the idea of a universal civil law state, they emphasize a fair and reasonable structure of society, where freedom is fully realized. Socio-historical progress is based on social history and legal progress, since without law, the progressive development of society and its social institutions is impossible [4].

The behavior of society members is the main feature that endowed with hierarchical power, whose action must be carried out strictly within the framework of the powers delegated by society to ensure socio-economic balance, including ensuring ecological balance. Consequently, the conditions for ensuring socioeconomic balance in ensuring the ecological balance must be met, which can be foreseen and built on the basis of foresight tools development as long-term forecasting.

\section{Materials and methods}

The study used the methods of deduction, induction, analysis and synthesis, logic and analogy, as well as the method of a systems approach.

\section{Research part}

Although the quality of life in an ecological balance determines the level of technological development, but the spiritual component in the evolution of society's needs has become a more stable driving force. The 
general conditions for ensuring socio-economic balance in ensuring the ecological balance from the position of foresight (FGser) can be reflected in the function of dependence with many factors influencing their formation, including: qualitative choice of representatives of hierarchical power from members of society to perform the functions of socio-economic balance in ensuring ecological balance for the whole society (flse-eb); formation and establishment of qualitative parameters and boundaries of the foresight authority of society management's hierarchical structure in ensuring the ecological balance (f2Psp-eb); implementation of high-quality monitoring and control over compliance with the parameters and boundaries of foresight powers in the hierarchical management structure (f3Kpsp-eb); determination and establishment of exceeding foresight powers level in the hierarchical structure of environmental balance management (f4Upsp-eb); determination and establishment of foresight of interdependencies observance level, conditionality's territorial, natural, national and traditional systemic nature of a particular society in environmental balance management (f5Upn-eb) and other foresight factors (fix-eb) in environmental balance management. General conditions of socio-economic balance in ensuring ecological balance from the foresight point of view (FGser) are shown in Figure 1.

Therefore, in order to comply with the general conditions of socio-economic balance in ensuring the ecological balance from the perspective of foresight (FGser), it is important to observe and take into account the factors that affecting the horizontal ecological balance level (FUNB) in socio-economic development and, accordingly, the possibility of using foresight tools. what should be reflected in the functional dependence (formula 1):

$$
\begin{aligned}
& F G_{s e r}=F U N B=f(f 1 s e-e b, f 2 P s p-e b, \\
& \left.f 3 K p s p-e b, f 4 U p s p-e b, f 5 U p n-e b, \ldots f_{i} x-e b\right)
\end{aligned}
$$

Of course, the society development evolution shows the desire of society to create tools for long-term forecasting, which should provide access to the "Golden Age", "Ideal State", "The Kingdom of Freedom." That is why the genesis of foresight tools as long-term forecasting and their evolution originates in the deep past of millennia, which is proved by the desire of ancient philosophy to look far into the future, laying the seeds of progressive ethics tree and morality in relation to "man's relation to nature."

Returning to the turn of ancient evolution, it is important to note that "divination" or "prophecy", from the position of Plato, does not contradict reason, science, but, on the contrary, is a "science of the future." According to Plato, "the science of the future" is governed by prudence, where it is important to be able to grasp the invisible features of the future - "signs" (according to the research of GI Marchenko). In antiquity, the nature of such an activity was called the art of divination, now - long-term forecasting, foresight [5].
Consequently, the desire to comprehend the passage of time in the future is reflected in the myths of antiquity, and then developed in the ideas of Socrates, Plato, Aristotle, Zeno. It is important to note that the religion schools (Judaism, Christianity and Islam) left in their scriptures a holistic view of predicting the longterm future - foresight. Consequently, the "foresight" definition ontology is revealed in the logical and philosophical sources of "long-term forecasting" that characterize foresight, determinism, cause and effect, probability and chance, possibilities and reality [6].

Foresight as a science of long-term forecasting has been actively developing since the beginning of the twentieth century and goes through several evolutionary stages at once, the most important of which are the "waves" of N.D. Kondratyev. N. D. Kondratyev was engaged in the formation of a methodology for long-term forecasting of the market economy and formulated the foundations of foresight theory. Evolving in modern research, the foresight ontology as a long-term forecasting is a reasonable conclusion from the experience gained to a possible outcome that has not yet occurred [7,8].

Research shows that already in 1930-1950. special foresight tools are formed as a functional tool for longterm forecasting. So, from 1930 to 1940 . in the forecasting system, economic planning is distinguished, due to the changing conditions of reproduction and the complication of the market economy. Further, in the forecasting system, a budgeting tool is being developed, which was developed in the 1940s - 1950s [9]. In the same period, the beginning of predictive research was laid: the development and use of forecasting theory and simple predictive models (1950s).

Total long-term forecasting (1960 - 1980) in the second half of the twentieth century determines the development of many theoretical questions, new methods, complex foresight models. Already from the 1980 s to the present, computer, communication and digital technologies have been intensively used. Of course, digitalization as a new stage in the development of socio-economic systems and forecasting their development has made it possible to form a sufficient theoretical basis with its own concepts, methods and tools. Digital transformation has gone a significant way from the inception of computers to the present time, defining the change of several technological paradigms $[10,11]$.

It is clear that the technological order affects all aspects of the evolutionary development of society, especially the processes of ensuring environmental safety. But now we are talking about the transition from Industry 4.0. to Industry 5.0 in the global community. Thus, the latest concept of digital transformation, presented by the technically advanced country of Japan, is already aimed at solving socio-economic and environmental problems in the process of integrating physical space with cyberspace and high technologies. Foresight forecasting determines that cyberspace and high technologies will ensure human life with security and convenience, where innovations are positioned as 


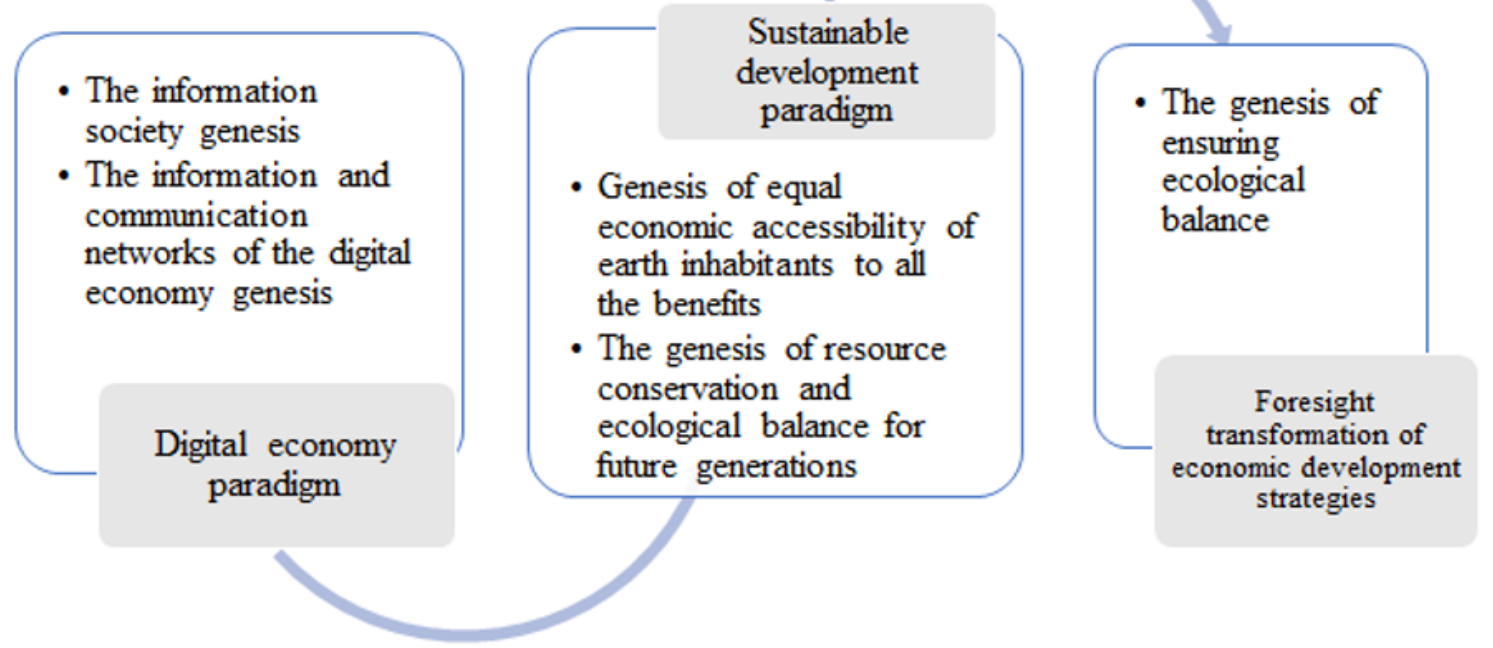

Fig. 2. Postulates of foresight strategies transformation of economic- society development in ensuring ecological balance.

environmentally friendly $[11,12]$, not violating the ecological balance and horizontal balance.

Another direction that determined the genesis of regional strategies foresight for socio-economic development in ensuring the ecological balance is the transition of the world community to sustainable development. The paradigm of sustainable development forces us to abandon the vector of economic growth (activity only for profit) and direct part of the income to restore the ecological balance. Accordingly, in such a stable paradigm, new methods of forecasting socioeconomic development will be formed.

The regional strategies foresight for socio-economic development in ensuring the ecological balance is considered as a continuous development that is based on scientific methods of cognition of the research area and the use of the entire set of methods, tools and means of economic forecasting [13, 14, 15].

Research shows that at present, ensuring security at the macro, meso and micro levels goes through the foresight of sustainable development, which will ensure ecological balance and resource conservation in the future. In the global policy of sustainable development, foresight presupposes a long-term transformation of the authorities' thinking, business, society about the essence of economic activity, which should not bring destruction to the ecological balance. Restoring the consequences of the facts of economic life as a path to sustainable development involves the cost of resources and time. So, at the UN conference G.Kh. Brutland proposed to consider "Sustainable Development" as a long-term continuous development that meets the needs of people living today, but takes place within the framework of preserving a clean environment for generations [16. 17, 18, 19]. Consequently, the sustainable development policy at the world level has three development directions, where the ecological vector is dominant.
Social and economic directions of development can be carried out only in the ecological balance.

That is why the sustainable development of the meso-level, namely the regions, becomes a priority for state regulation of mechanisms that stimulate, restrictive, taking into account the economic specifics of politics, socio-economic and territorial situation, the mentality of the region's population.

Consequently, the main directions of modern research on the strategy of region economic development should be carried out taking into account economic paradigms and revolutionary shifts. The paradigms of the digital economy and sustainable development are driving technological shifts. As a set of a single technical level used in the production process and the synchronously developing "technological order" of society corresponds to the achievements of scientific and technological progress and social technological thinking [20, 21, 22, 23].

The desire for technological changes in the way of life of the region postulates a new evolutionary round, which presupposes the economic development of society in the context of sustainable development paradigm. The paradigm of sustainable development determines equal economic accessibility to various benefits for all people living on earth. The attitude to profit in the process of carrying out economic activities becomes revolutionary. The revolutionary principle of sustainable development paradigm determines the focus on respect for resources in the economic development process, as well as compensation for damage to the ecological balance at the expense of the profit or other income. The formation of a new information economic society in the context of sustainable paradigms development and the digital economy determines the transformation of the constituent parts of foresight strategies as a source of creating the main accumulation of wealth and ensuring the population well-being. 
The postulates of foresight transformation strategies for the economic development of society in ensuring the ecological balance are presented in Figure 2.

In the digital economy, new forms of online exchange between consumers (customers) and manufacturers (suppliers) of all types of products (goods, works, services, information) determine the implementation of a progressive method of resource conservation and modification, which is aimed at the whole world in a sustainable development

The integration of digital economy technologies and cognitive approaches to a lean economy, resource conservation and modification established by sustainable development allows:

integrate computer systems, information and communication technologies, broadband Internet into the life of the entire population of the regions, country, mainland, planet (conditions of the paradigm of the information society and digital economy);

integrate new forms of online exchange between consumers (customers) and manufacturers (suppliers) of all types of products (goods, works, services, information) (conditions of the information society and digital economy paradigm);

integrate digital government services - e-government - to inform and provide all services to the population by federal, regional, local authorities (conditions of the information society and digital economy paradigm);

to significantly reduce the overstocking of warehouses with products that may not be realized or become unsuitable for the expiration of the shelf life for use, which will save resources or carry out product modifications in the required time (conditions of the sustainable development paradigm);

to totally apply the custom-made method in the process of meeting needs, taking into account the increase in consumer waiting periods (conditions of the sustainable development paradigm);

provide equal access to all residents to information about the benefits and opportunities from acquisition (conditions of the sustainable development paradigm).

\section{Final part}

Foresight of regional strategies of socio-economic development in ensuring an ecological balance involves the application of the principles of increasing the deadlines and expectations between the producer and the consumer:

1) in the process of building a custom-made method upon request for numerous necessary products (goods, works, services, information);

2) in the willingness of consumers to postpone the period of meeting needs with products (goods, works, services, information) due to their quality, deep processing of resources, as well as reducing excessive overstocking and prices.

Such an information and communication form of the relationship between the manufacturer and the consumer should be incorporated into the foresight as the main way of providing quality orders that ensure responsible consumption while maintaining an ecological balance on the platform of new technologies and an unlimited scale of business models.

The study showed that the desire to ensure an ecological balance predetermines the improvement of household items, means of labor, and an increase in production capacity. It is the paradigm of sustainable development in the future that directs the entire society to improve the quality of products (goods, works, services), increases their safety in use. Foresight of highquality services in the non-market sphere is important in ensuring the ecological balance: health protection, life, education, development of digital telecommunications infrastructure, environmental protection. It is clear that taking into account the trends in the directions of modern economic development in the context of sustainable development paradigms and the digital economy will allow obtaining a synergistic effect, which is manifested in an increase in the quality of life when using safe technologies and products, which will also be the driver of the beginning of transition process to a new technological order.

It is advisable to manage the economic development of the region taking into account the many features that define the region as a dynamic stochastic system, where regional policy should be aimed at a foresight strategy in detail with short-term interests. It is necessary to provide a process for resolving conflicts of priority between foresight strategies for ecological balance and current decisions $[21,22,23]$. However, priority conflicts can be smoothed out according to the results of qualitative and quantitative data analysis, structural links between variables or components of the regional system, in the assessment of the main policy of environmental, social, cultural, economic development.

It is important to note that in complex dynamical systems, the results are mostly separate in time and space. That is why resistances and reverse (negative) connections arise. The solution to this problem is to identify the boundaries of mental models in such a way that it will make it possible to realize possible resistances (feedbacks) that may appear in the future from the results of regional governance. Undoubtedly, system analysis as a tool for justifying the foresight model of ensuring the ecological balance of the region includes hierarchical levels in simulation models as a set of flows (financial, labor, product, etc.), where two elements are distinguished: a network of flows and a network of information. Therefore, it is necessary to analyze and assess the structure and dynamics of the increasingly complex systems of the region (meso level), which is part of the country (macro level), and at the same time includes cities, districts, villages (local level) and economic entities (micro level).

\section{Conclusion}

The system undergoes continuous restructuring in constant change of phases and ultimately self-organizes, acquiring relative stability, acquiring a state of equilibrium (ideal conditions for the economic system of 
the region). However, in real mode, the economic system cannot find a state of equilibrium. Each complex system constantly strives for balance by means of control actions, where only "moments" of balance appear, which are immediately violated. Such conditions can be called dynamic economic equilibrium, which determines evolutionary processes. Also, system modeling allows you to explore several options for the development of the future, highlighting risks, subjective and objective, internal and external factors, criterion and indicators.

Making a conclusion, it is important to note that in the regional economic development foresight as a complex system, dynamic modeling becomes the most widely used method in the process of solving the identified problems. At the same time, the control of complex systems has a limitation in the accuracy of modeling and the impossibility of predicting a priori estimate. However, with the help of dynamic modeling, it is advisable to diagnose complex systems to establish cause-and-effect relationships, as well as to predict resistances to changes in foresight strategies in managing a dynamic system, identifying the necessary competencies for specialists involved in the process of building regional economic development.

\section{References}

1. V.N. Sadovsky, Change of paradigms of systems thinking / Systems research. Methodological problems. - M.: Editorial URSS (1996)

2. Yu.V. Ragulina, N.A. Lebedev, Certain directions of innovative evolution processes in the industry of macroregions // Global scientific potential, 9, 42, 70-74 (2014)

3. N.N. Nikulina, The origins of the idea of progress in the creative heritage of European thinkers of antiquity and the Middle Ages, Bulletin of the Murmansk State Technical University, 14, 2, 410417 (2011)

4. S.I. Arkhipov, Ideas about the legal progress of I. Kant and G.V.F. Hegel, Electronic Supplement to the Russian Law Journal, 1, 7-18 (2018)

5. G.I. Marchenko, Plato on Prophecy as Political Consulting, Power, 6, 52-159 (2016)

6. T.V. Schenknecht, Logic and philosophical foundations of linguistic forecasting, World of Science, Culture, Education, 7 (19), 74-78. (2009)

7. E.V. Postnikova, Forecasting skills formation among students of economic profile, Bulletin of the Samara State University, 5/2, 45, 69-75 (2006)

8. E.A. Samburov, A.E. Kaschaev, N.S. Konoplev, The role of dialectics principles in the theory of foresight, Discussion, 2 (32), 28-32 (2013)

9. S.A. Beskorovainaya, Sphere of economic planning's evolutionary processes as a theoretical aspect of determining the place of budgeting in the functional of financial management, International accounting, 25, $20-26$ (2012)
10. A.V. Shokhnekh, , Y.V. Melnikova, T.M.Gamayunova, The Investment Concept Strategy of Development of Innovative Activities of Agricultural Organizations in the Conditions of Techno-Economic Modernization, Lecture Notes in Networks and Systems, 87, 796-808 (2020)

11. Yu.I. Gribanov, Key of theory aspects and methodology of of socio-economic systems' digital transformation, Bulletin of the Altai Academy of Economics and Law, 2, 83-89, (2009)

12. V.V. Krivorotov, A.V. Kalina, A.I. Savelieva, A.Yu. Bayranshin, Forecasting the development of regional industrial complexes, Bulletin of UrFU. Series: Economics and Management, 4, 99-111 (2011)

13. A.V. Shokhnekh, Modeling of tax levers for managing the level of environmental and food security in the regions, Audit and financial analysis, 1, 33-37 (2016)

14. Y.V. Melnikova, A.V.Shokhnekh, Forming the Policy of Insurance of Innovative and Investment Activities of Agricultural Organizations as a Concept-Strategy of Provision of Economic and Food Security, Lecture Notes in Networks and Systems, 87, 809-816 (2020)

15. Panov, N. Panova, A.Malofeev, E. Nemkina, Interaction of regional agribusiness entities in the transition to a digital economy, IOP Conference Series: Earth and Environmental Science, 403, 1 (2019)

16. T. Kosulnikova, L. Sizeneva, D. Sharapov, M. Semenova, Cluster approach to development of wine and gastronomy tourism in Volgograd region, E3S Web of Conferences, 175, 10017 (2020)

17. L.A. Sizeneva, A.V. Dyachenko, T.L. Kosulnikova, The metatheoretical study of the tourism system of the Volgograd Region and the study of preferences of consumers of regional tourism products, International Journal of Engineering and Technology(UAE), 7(4), 502-514 (2018)

18. N.Ivanova, M. Ovchinnikov, M. Lata, I. Korabelnikov, Digital Agriculture: Opportunities for the Development of Small Agribusinesses and the Respective Problems, Lecture Notes in Networks and Systems, 111, 593-600 (2020)

19. G.H. Brutland, Our common future. Report of the UN Commission on Environment and Development (1988)

20. V.V. Silakova, The sixth technological order and the economic mechanism of risk management in continuous industries, Economics in industry, 10, 4, (2011)

21. O.Yu. Selyutina, Structural dynamic model of regional socio-economic development, Statistics and Economics, 4 (2011)

22. G.I.Sidunova, A.V. Shokhnekh, A.A. Sidunov, O.S. Glinskaya, L.A. Sizeneva, Approaches to 
modeling management and control processes in foresight management system taking into account expresentness conditions, Espacios, 38, 24, 30 (2017)

23. N.M.Karaulova, L.A.Sizeneva, Elementary unit of mechanism of interests implementation of economic intercourse subjects, World Applied Sciences Journal, 30, 10, 1380-1383 (2014). 